NASA/TM-2006-214233

\title{
Demonstration of an Ice Contamination Effects Flight Training Device
}

Thomas P. Ratvasky

Glenn Research Center, Cleveland, Ohio

Richard J.Ranaudo

University of Tennessee Space Institute, Tullahoma, Tennessee

Kurt S. Blankenship

Glenn Research Center, Cleveland, Ohio

Sam Lee

QSS Group, Inc., Cleveland, Ohio 


\section{NASA STI Program . . . in Profile}

Since its founding, NASA has been dedicated to the advancement of aeronautics and space science. The NASA Scientific and Technical Information (STI) program plays a key part in helping NASA maintain this important role.

The NASA STI Program operates under the auspices of the Agency Chief Information Officer. It collects, organizes, provides for archiving, and disseminates NASA's STI. The NASA STI program provides access to the NASA Aeronautics and Space Database and its public interface, the NASA Technical Reports Server, thus providing one of the largest collections of aeronautical and space science STI in the world. Results are published in both non-NASA channels and by NASA in the NASA STI Report Series, which includes the following report types:

- TECHNICAL PUBLICATION. Reports of completed research or a major significant phase of research that present the results of NASA programs and include extensive data or theoretical analysis. Includes compilations of significant scientific and technical data and information deemed to be of continuing reference value. NASA counterpart of peer-reviewed formal professional papers but has less stringent limitations on manuscript length and extent of graphic presentations.

- TECHNICAL MEMORANDUM. Scientific and technical findings that are preliminary or of specialized interest, e.g., quick release reports, working papers, and bibliographies that contain minimal annotation. Does not contain extensive analysis.

- CONTRACTOR REPORT. Scientific and technical findings by NASA-sponsored contractors and grantees.
- CONFERENCE PUBLICATION. Collected papers from scientific and technical conferences, symposia, seminars, or other meetings sponsored or cosponsored by NASA.

- SPECIAL PUBLICATION. Scientific, technical, or historical information from NASA programs, projects, and missions, often concerned with subjects having substantial public interest.

- TECHNICAL TRANSLATION. Englishlanguage translations of foreign scientific and technical material pertinent to NASA's mission.

Specialized services also include creating custom thesauri, building customized databases, organizing and publishing research results.

For more information about the NASA STI program, see the following:

- Access the NASA STI program home page at http://www.sti.nasa.gov

- E-mail your question via the Internet to help@sti.nasa.gov

- Fax your question to the NASA STI Help Desk at 301-621-0134

- Telephone the NASA STI Help Desk at 301-621-0390

- Write to:

NASA STI Help Desk

NASA Center for AeroSpace Information 7121 Standard Drive Hanover, MD 21076-1320 
NASA/TM-2006-214233

AIAA-2006-0677

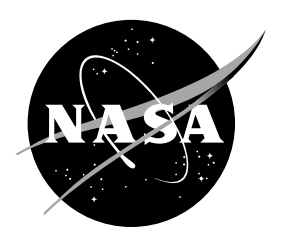

\section{Demonstration of an Ice Contamination Effects Flight Training Device}

Thomas P. Ratvasky

Glenn Research Center, Cleveland, Ohio

Richard J.Ranaudo

University of Tennessee Space Institute, Tullahoma, Tennessee

Kurt S. Blankenship

Glenn Research Center, Cleveland, Ohio

Sam Lee

QSS Group, Inc., Cleveland, Ohio

Prepared for the

44th Aerospace Sciences Meeting and Exhibit

sponsored by the American Institute of Aeronautics and Astronautics

Reno, Nevada, January 9-12, 2006

National Aeronautics and

Space Administration

Glenn Research Center

Cleveland, Ohio 44135 


\section{Acknowledgments}

The authors wish to thank Gary Nolan from NASA Glenn's Imaging Technology Center and Billy Barnhart and Mike Chriest from Bihrle Applied Research for their valuable contributions and timely responses in developing this icing training tool. We are grateful to the University of Tennessee's Department of Continuing Education for their outstanding and friendly support in putting the short courses together. Lastly, thanks to the sponsors from the System Wide Accident Prevention Project for their continued support during this demonstration cycle.

Trade names and trademarks are used in this report for identification only. Their usage does not constitute an official endorsement, either expressed or implied, by the National Aeronautics and Space Administration.

Level of Review: This material has been technically reviewed by technical management.

Available from

NASA Center for Aerospace Information 7121 Standard Drive

Hanover, MD 21076-1320
National Technical Information Service 5285 Port Royal Road Springfield, VA 22161 


\title{
Demonstration of an Ice Contamination Effects Flight Training Device
}

\author{
Thomas P. Ratvasky \\ National Aeronautics and Space Administration \\ Glenn Research Center \\ Cleveland, Ohio 44135 \\ Richard J. Ranaudo \\ University of Tennessee Space Institute \\ Tullahoma, Tennessee 37388 \\ Kurt S. Blankenship \\ National Aeronautics and Space Administration \\ Glenn Research Center \\ Cleveland, Ohio 44135 \\ Sam Lee \\ QSS Group, Inc. \\ Cleveland, Ohio 44135
}

\begin{abstract}
The development of a piloted flight simulator called the Ice Contamination Effects Flight Training Device (ICEFTD) was recently completed. This device demonstrates the ability to accurately represent an iced airplane's flight characteristics and is utilized to train pilots in recognizing and recovering from aircraft handling anomalies that result from airframe ice formations. The ICEFTD was demonstrated at three recent short courses hosted by the University of Tennessee Space Institute. It was also demonstrated to a group of pilots at the National Test Pilot School. In total, eighty-four pilots and flight test engineers from industry and the regulatory community spent approximately one hour each in the ICEFTD to get a "hands on" lesson of an iced airplane's reduced performance and handling qualities. Additionally, pilot cues of impending upsets and recovery techniques were demonstrated. The purpose of this training was to help pilots understand how ice contamination affects aircraft handling so they may apply that knowledge to the operations of other aircraft undergoing testing and development. Participant feedback on the ICEFTD was very positive. Pilots stated that the simulation was very valuable, applicable to their occupations, and provided a safe way to explore the flight envelope. Feedback collected at each demonstration was also helpful to define additional improvements to the ICEFTD; many of which were then implemented in subsequent demonstrations.
\end{abstract}

\section{Nomenclature}

$\begin{array}{ll}\text { AvSSP } & \text { Aviation Safety and Security Program } \\ \text { CAST } & \text { Commercial Aviation Safety Team } \\ \text { CLC } & \text { Control Loading Computer } \\ \text { DME } & \text { Distance Measuring Equipment } \\ \text { FCS } & \text { Fokker Control System } \\ \text { HQR } & \text { Handling Quality Rating } \\ \text { HSI } & \text { Horizontal Situation Indicator } \\ \text { ICEFTD } & \text { Ice Contamination Effects Flight Training Device } \\ \text { ICTS } & \text { Ice Contaminated Tailplane Stall } \\ \text { SWAP } & \text { System Wide Accident Prevention Project } \\ \text { UTSI } & \text { University of Tennessee Space Institute }\end{array}$


$\delta \mathrm{F} \quad$ Flap Angle

\subsection{Introduction}

NASA's Aviation Safety and Security Program and the CAST Loss of Control Joint Safety Analysis Team identified icing as a contributing factor in a significant number of recent fatal accidents (ref. 1). Several highly-ranked interventions and research recommendations addressed the need for upset recovery training with high-fidelity simulation and the requirement for improved aerodynamic modeling at the stall and post-stall region of the envelope.

Through the sponsorship of AvSSP's SWAP, NASA Glenn's Icing Branch teamed with Bihrle Applied Research and the Wichita State University in 1998 in a program to develop an icing effects flight training device concept demonstrator. The objective of the program was to develop a methodology for deriving and validating icing effects simulation models, and to demonstrate the utility of using this device for training pilots to recognize and recover from the hazardous flight characteristics caused by aircraft icing. Since the ICEFTD was developed and tested, ongoing evaluations have been conducted to determine the value of this technology for incorporation into other flight training simulators. The capability for including icing effects into flight training simulators used for initial and recurrent training will allow pilots to experience representative icing-induced aircraft handling characteristics, especially in failure case training scenarios. Presently, icing effects in even the most sophisticated flight simulators are simple models that do little more than increase aircraft weight to simulate in-flight icing. Realistic icing simulator models however, based on aerodynamic effects of airframe icing will enhance safety by allowing pilots to recognize important visual and tactile cues associated with an icing event. Currently, pilots only experience the effects of an ice protection system failure for the first time in a real flight situation. As in stall and windshear training, improved icing flight simulation will better equip pilots to employ the correct procedures and techniques to affect a recovery to a safe flight condition.

The process to develop the icing flight training device was previously reported in various reports (refs. 2 through 6) and included aspects of wind tunnel testing for aerodynamic scaling of ice shapes, wind tunnel testing for complete airplane aerodynamics, flight simulation modeling, and flight test for simulation validation. The airplane chosen for this activity was a DeHavilland DHC-6 Twin Otter since NASA had extensive operational experience in icing conditions with this airplane and the Twin Otter has a known sensitivity to ICTS.

This report describes the current configuration of the ICEFTD and how it was used to demonstrate this technology development at three recent icing short courses held at the UTSI and one demonstration at the National Test Pilot School. Specifically, the training syllabus elements and how they were implemented are discussed. Pilot feedback on the value of the flight training device is also discussed. Lastly, remarks on potential future directions are shared.

\subsection{Ice Contamination Effects Flight Training Device Description}

\subsection{Background}

The original intent of the project was to develop a desktop simulation of icing effects on a DHC-6 Twin Otter that was described in reference 6. However, after discussion with several NASA pilots and considering principles of cognitive science discussed in reference 7 , it was determined that some improvements in the assembly of the hardware components would lead to a better habit transfer to the training pilots. The issue with the desktop simulation was on the method of habit transfer, not on the content. Pilots reactions based on the desktop presentation tended to be dismissive. The desktop simulation approach was considered to be more or less a game, even though the content (simulation) was accurate. We felt that improving the simulation environment would increase the pilot's confidence in the information being transferred through the simulation. This was achieved by isolating the pilot in a cockpit environment with visual, tactile, and display cues that support aircraft motion and control system 
characteristics. As a result, the concept of a flight training device in which the pilot could be fully engaged was developed.

\subsection{Basic Physical Description}

The ICEFTD is a fixed-base flight training device that is configured for pilot familiarization of typical effects of aircraft icing. The basic device (fig. 1) consists of a raised platform and framework that supports a pilot seat, a control yoke, rudder pedals, a twin turbo-prop throttle quadrant, three flat panel monitors for out-the-window graphics, and two additional flat panel monitors for instrument panel graphics. The control column is connected to a programmable loader for longitudinal force feedback, whereas the yoke (lateral) and rudder pedals force gradients are provided by spring resistance. Two PC's host the simulation models and control the graphics. A third PC, the CLC, controls the electro-mechanical loader to simulate representative column forces (see section 2.5). These PC's are mounted under the "floor" of the device and the control loader device is mounted to the frame forward of the pilot's feet. A curtain surrounds the ICEFTD to isolate the pilot from external visual distractions. All of the electrical devices are connected through a daisy-chained series of electrical power strips/surge protectors so that only a single $110 \mathrm{~V}$ wall socket is needed to power the entire device. The platform is $33.5 \mathrm{in}$. wide by $84 \mathrm{in}$. long, and weighs $450 \mathrm{lb}$. It has 4 caster wheels for easy transporting and screw down feet to lock down for demonstrations. This design is well-suited for mobility and usability at various settings - from labs or offices to class rooms or hangars.

An instructor station is set up on a table directly behind the ICEFTD (figs. 2 and 3). The instructor station consists of a laptop computer to provide control of the simulation (initial conditions, start, stop, etc.), video recording and monitoring devices, and an intercom system for communications between the training pilot and the instructor. A second laptop computer is used to transcribe pilot comments and relevant notes during the simulation sessions.

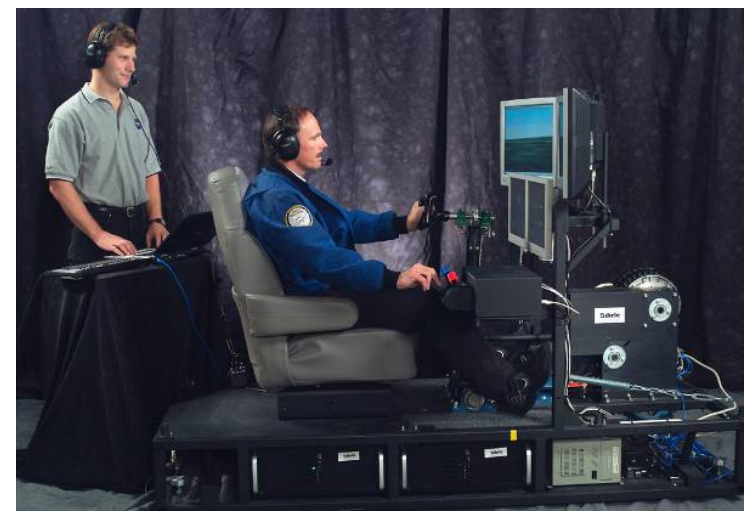

Figure 1.-Ice contamination effects flight training device.

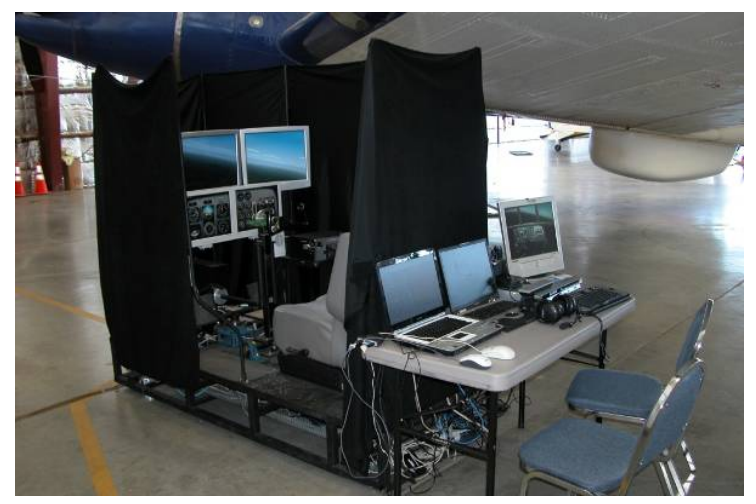

Figure 2.--Ice contamination effects flight training device setup with instructor Workstation.

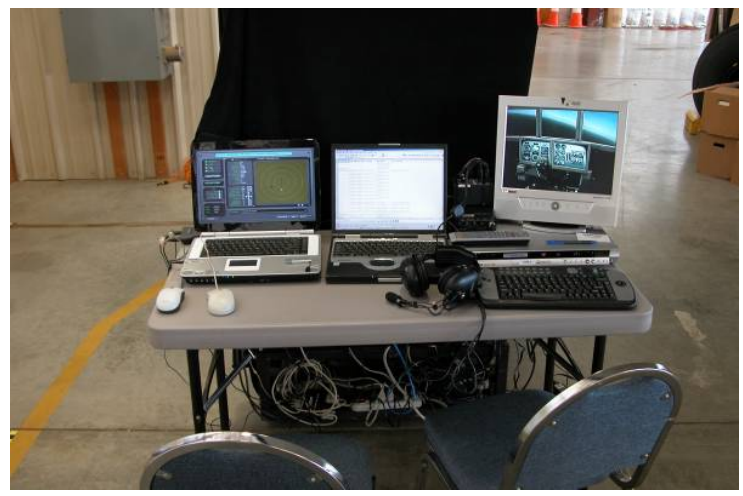

Figure 3.--Instructor workstation. 


\subsection{Flight Simulation Software}

The key component that integrates the ICEFTD is the simulation software called D-Six ${ }^{\circledR}$, a commercial off-the-shelf product from Bihrle Applied Research, Inc. D-Six is a PC based simulation environment that combines the graphical interface, analysis tools and flexibility of the simulation development environment with the computational power needed to run complex engineering simulations in real time. D-Six fully supported the Twin Otter no-ice baseline and failure ice shape simulation development, analysis and validation activities as described in references 3 and 4. Moreover, D-Six is the primary driver in the real-time, "pilot-in-the-loop" simulations that are executed with the ICEFTD hardware. Pilot inputs consist of column, yoke, rudder pedal, and throttle deflections as well as flap angle selection. These pilot inputs are transformed into control surface deflections which, along with initial aircraft states, are read by D-Six to derive aircraft forces and moments based on the Twin Otter simulation models. The simulation models include:

- aerodynamic models for the baseline (No-Ice), a Horizontal Tail Failure Ice Shape, and an AllIced Failure Shape (wings, horizontal, and vertical tail) - based on wind tunnel testing of 6.5 percent-scale model of a Twin Otter

- propulsion model - based on Twin Otter engine deck and propeller charts

- elevator hinge moment/column force model - based on full-scale wind tunnel tests of Twin Otter horizontal tail model.

- generic landing gear model - to enable taxi, take-off and landing operations

Using these models, D-Six then outputs new states based on the equations of motion and updates the out-the-window and control panel graphics as well as control loads to the pilot, all in real time.

\subsection{Graphics}

D-Six also provides a full-screen multi-channel display application, taking advantage of Windows multi-screen capability. This feature is used for the out-the-window graphics, which use 3 screens, and the control panel graphics, which use 2 screens. In this way, the training pilot only views the scenery or instrument panel displays - not the simulation software control panels. These are present on the screens, but operate in the background.

The out-the-window view (fig. 4) is generated from a generic terrain model and includes features such as an airport, buildings, trees, and varied terrain elevations. Also sky conditions, based on time of day and cloud bases and tops, are fully programmable. The cloud functions are a key feature used in the scenario-based training module. Winds, turbulence and wind shear are also configurable within D-Six's environmental settings.

The instrument panel graphics (fig. 5) were designed to represent traditional round dial instrument displays typically found in general aviation airplanes with airspeed, attitude, altitude, vertical speed, heading, and turn/bank indicator instruments. Torque pressure, flap position, and elevator trim tab position indicators are also provided. HSI, DME indicator, and marker beacon indicators were also represented to enable precision approaches to be executed as part of the scenario-based training module. An instrument landing system is modeled for one approach to a generic airport within the terrain model. This model is used to drive the glide slope and localizer needles on the HSI and to trigger marker beacon events - flashing lights and sounds. Based on feedback from early demonstrations, a stall warning light and horn and a G-meter were added to provide additional cues to the pilot.

Because of the large demand for CPU time to drive three out-the-window graphic screens, a single PC was unable to host the simulation software and drive all the graphics. Therefore the workload was split so that one PC (ICE01) runs D-Six to host the simulation models and drive the instrument panel graphics while a second PC (ICE02) runs a second copy of D-Six in order to drive the out-the-window graphics. Communications between these two computers are through an Ethernet local area network. 


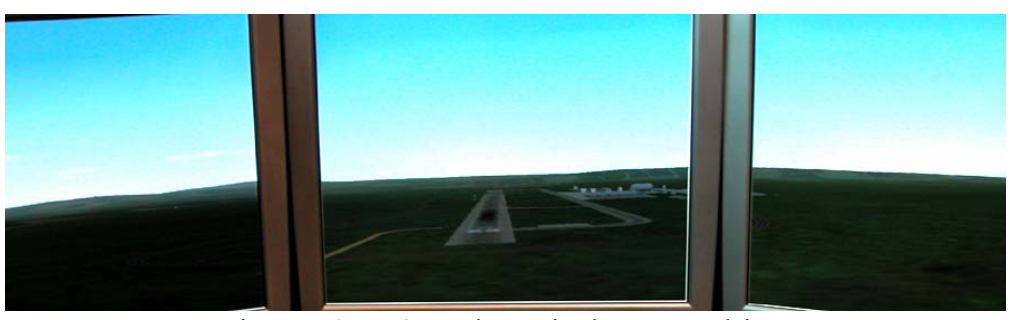

Figure 4.- Out-the-window graphics.

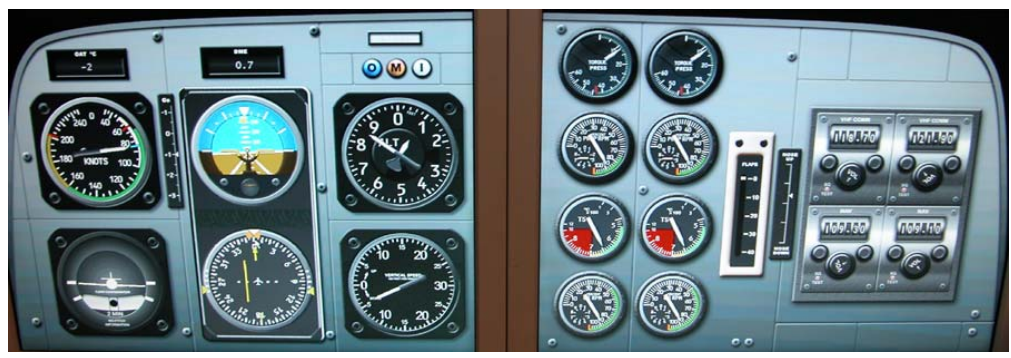

Figure 5.- Instrument panel graphics.

\subsection{Column Force Control Loader}

Based on previous research on ice contaminated tailplane stall using the NASA Twin Otter (ref. 8), it was clear that any simulation of tailplane stall required force-feedback in the control column. Column forces experienced in the NASA/FAA Tailplane Icing Program were as high as $180 \mathrm{lb}$ during one recovery maneuver and were an essential cue to pilots of an impending tail stall event.

For these reasons, a FCS electro-mechanical stick loader was specified for the ICEFTD. The FCS loader supplies longitudinal stick feel for the control column and provides column position and column force to the simulation through exchange of parameter arrays over the Ethernet LAN network between the ICEFTD computers. A D-Six module on the ICE01 PC interfaces with the FCS system through an Ethernet LAN to the CLC. D-Six calculates stick force intercepts and gradients from elevator hinge moment tables. This data is transferred to the CLC which then commands the loader. The yoke height and column deflection limits were matched to those of the Twin Otter so that pilot forces and range of motion would be representative of the simulated aircraft.

One key feature of the D-Six module and FCS system combination is the ability to activate and model stick shaker parameters. Although the stick shaker function is typically used as an electronic stall warning device, it was resourcefully used in the ICEFTD to provide tactile feedback due to unsteady flow conditions over the horizontal tailplane. Flow separation and reattachment on the lower surface of the iced tailplane causing transient variations in the control forces were measured in previous NASA flight programs with the Twin Otter. The transient nature of these elevator deflections was analyzed to understand the frequency and amplitude during impending tail stalls. This information was used to create a table in D-Six to actuate the "stick shaker" feature of the FCS loader when the conditions for tail stall were present in the simulation. Typically, the frequency was below $3 \mathrm{~Hz}$ and the amplitude in the column was less than $2 \mathrm{in}$. In this manner, the training pilot would not only be exposed to the nominal changes in stick force gradient due to tailplane icing, but the transient force changes due to the unsteady flow conditions as well.

\subsection{Instructor Laptop}

An instructor's laptop was developed to interface with the D-Six model host and graphics computers to enable an easy-to-use set of controls. In this way, the instructor would not need detailed knowledge of the D-Six software. The instructor laptop uses a GUI designed with Macromedia Director to enable 


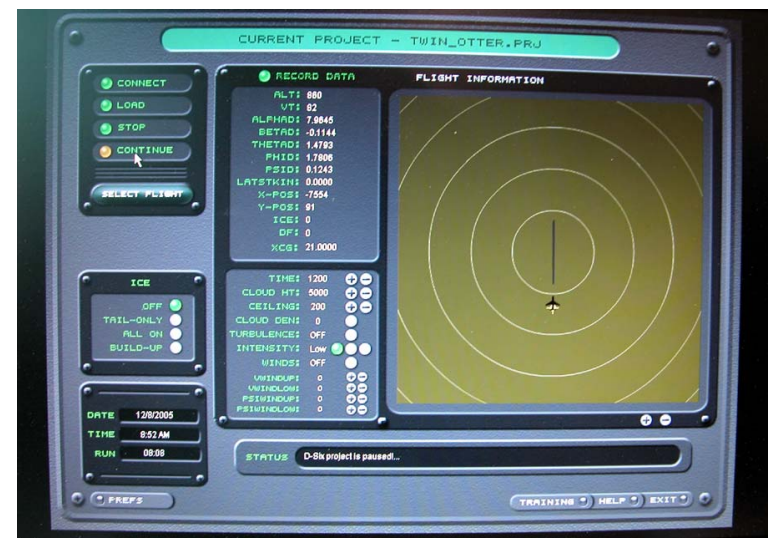

Figure 6.--Instructor's laptop GUI.

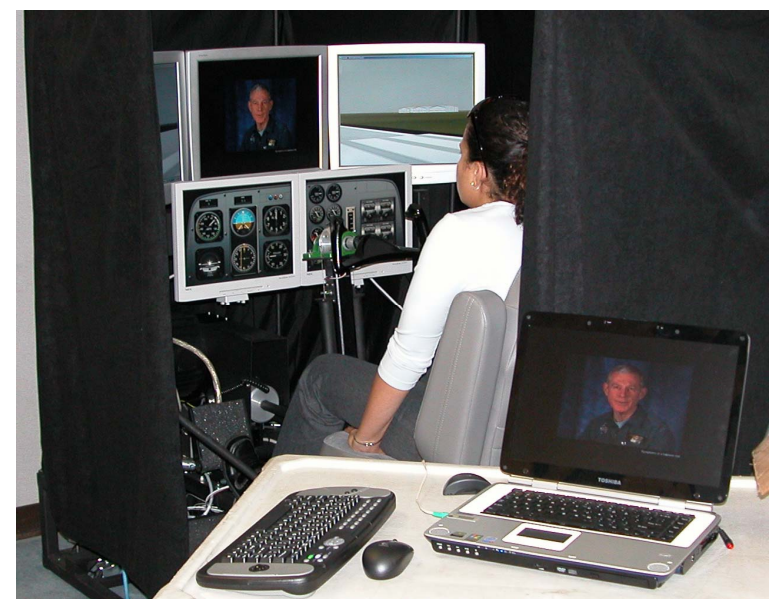

Figure 7.-Multi-media training material to reinforce hands on training.

loading the D-Six project on the ICEFTD computers, setting up initial conditions for the simulator session, and starting/stopping the sessions (fig. 6). The GUI provides radio buttons to set up predefined initial conditions per a training syllabus. It also has switches to turn on/off clouds, winds, turbulence and to set the icing configuration (No-Ice, Tail Ice, All Iced), cloud height and depth, wind speed and direction, center of gravity, and the time of day. During the training sessions, flight parameters are displayed to the instructor in text, and the airplane position and heading are represented on a map display. This allows the instructor to provide direction similar to an air traffic controller, particularly in the scenario-based training sessions. Lastly, during the training sessions, certain flight parameters are recorded in an ASCII file on the instructor laptop for later analysis and discussion with the training pilot. Example plots are shown in the demonstration section.

Another key feature of the GUI is the capability to introduce multi-media training material to reinforce the practical lessons provided by the ICEFTD. At the instructor's discretion, video clips from NASA's "Tailplane Icing" (ref. 9) and "Icing for General Aviation" (ref. 10) can be shown to the training pilot on the center screen of the ICEFTD using a simple video switch (fig. 7). The video clips describe various aspects of tailplane stall and wing stall, including cues of impending stalls and recovery techniques. These clips emphasize relevant learning points by showing graphics of fundamental concepts, in-flight videos, and pilot testimonials describing events similar to what the training pilot just experienced in the ICEFTD.

\subsection{Demonstrations of the ICEFTD}

\subsection{General Background on the Demos}

Four formal demonstrations of the ICEFTD took place between October 2004 and November 2005. In total, eighty-four pilots and flight test engineers from the industry, regulatory and military communities received practical lessons on an iced airplane's reduced performance and handling qualities.

The first two demonstrations were held in October 2004 and May 2005 at the University of Tennessee Space Institute in Tullahoma, Tennessee. Twenty-four pilots and flight test engineers from Bombardier, Cessna, Raytheon, US Army, US Forestry Service, the FAA, and Canada's Transportation Safety Board participated in the In-Flight Icing and Its Effects on Aircraft Handling Qualities short course. This short course consisted of lectures, a flight in the UTSI Navion variable stability airplane (fig. 8), and a simulator session in NASA's ICEFTD (fig. 9). 


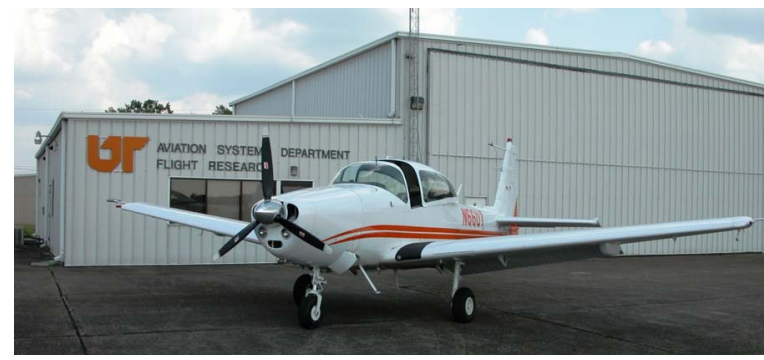

Figure 8.-UTSI variable stability Navion.

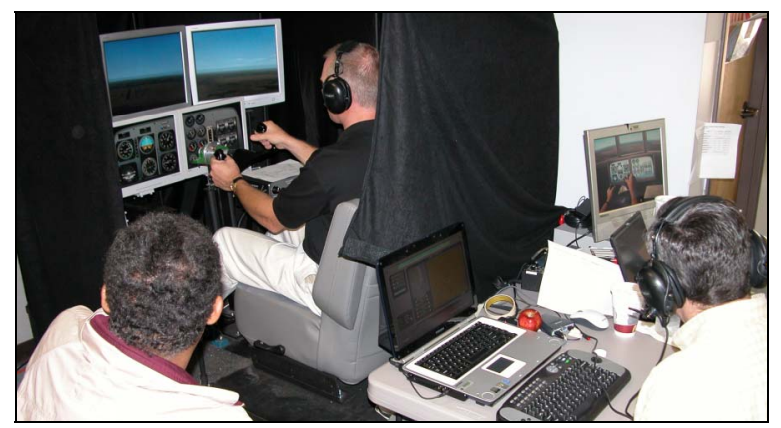

Figure 9.--Demonstration of ICEFTD at UTSI.

This forum provided an excellent opportunity to demonstrate the ICEFTD capabilities. The lecture materials were relevant, and the Navion flights provided an in-flight simulation of degraded flying qualities due to icing. The Navion was programmed to handle as the NASA Twin Otter in specific configurations and tail ice shapes using NASA's stability and control database on the Twin Otter. Participants would fly from the Navion's left seat where irreversible control inputs were made into an analog computer. These pilot inputs were translated into control surface inputs to generate the handling characteristics that were pre-programmed. The Navion provided a multi-sensory representation of the iced aircraft handling issues very well. However, it did not provide control column force feedback or enable upset recovery procedures to be practiced. Alternatively, the ICEFTD offered a fixed-base simulation of the Twin Otter with various forms of icing that enabled pilots to identify cues of impending wing and tail stall events and develop control strategies for recovery. The force feedback feature in the ICEFTD provided critical cues to identify and recover from tail stall. However, the ICEFTD did not provide the vestibular cues that are another valuable source of information to pilots. Despite these differences, the Navion flights and ICEFTD sessions were complimentary and offered unique practical experiences on the effects of ice on aircraft flying qualities.

Group discussions at the end of the courses provided valuable feedback on benefits of the training provided though the ICEFTD. Most pilots were astonished by the degraded flying characteristics caused by icing and relationship that configuration and power changes had on those characteristics. The ICEFTD put context to the NASA's "Tailplane Icing" educational video by representing the large physical loads exerted by the pilot during control force reversals caused by tail stall and the procedures needed for recovery. Additionally, pilots who flew the ICEFTD prior to the Navion felt it prepared them for the Navion flights by setting expectations of the reduced controllability.

Participants also suggested some improvements in the ICEFTD. After the first demonstration, audio files of the Twin Otter prop and engine noise, stall warning, and marker beacons were added to the simulator. Headsets were also used in future demonstrations. By adding these features, pilots were more engrossed and focused on the simulation rather than being distracted by ambient noises and discussions that took place by observers. Other improvements included increasing stick force per G, adding stall warning, G-meter, and trim tab indicators to the instrument panel. All of these improvements provided better cuing to the pilots, which led to better training.

The third demonstration took place at the National Test Pilot School in Mojave, California in October 2005. The ICEFTD was demonstrated as part of the one-year professional test pilot program and several short course offerings. Nineteen pilots (mostly international military) and flight test engineers were exposed to the Twin Otter icing flight characteristics. Unlike the previous demonstrations, this was not a forum focused on icing. Because of this, the video segments available in the ICEFTD were used more extensively to support the simulator sessions and emphasize the icing effects on stall characteristics and controllability. Many pilots were simply amazed at the amount of control difficulties caused by ice and were grateful to experience these problems in the simulator.

The fourth demonstration was held in November 2005 as part of the UTSI Aircraft Icing Short Course in Wichita, Kansas. Eighty-nine pilots and engineers from Bombardier, Cessna, Raytheon, and the 
FAA attended this short course. It consisted of two days of lectures followed by a simulator session in the ICEFTD for forty-one of the participants. Each was scheduled a one-hour session during the week following the lectures. The ICEFTD was set up at the Wichita Area Technical College - an ideal location because it had ample classroom space and was convenient for the participants.

The demonstration in Wichita was the most extensive of the four demos. As such, the remaining sections will expand on the process used and the results from this demonstration.

\subsection{Training Sessions}

Before each training session, pilots were given a briefing to:

- show the full-scale ice shapes used in the ICEFTD development and validation,

- review the various training profiles to be accomplished in the training session,

- remind the pilots that the aircraft characteristics shown are unique to the DHC-6 and that some configurations used in the training were outside of the manufacturers limitations as provided in the Airplane Flight Manual,

- review the pilot controls and instrument displays on the ICEFTD.

Once the pilot was comfortably seated in the ICEFTD, the video recording was started and the training profiles were initiated.

The training profiles consisted of three blocks. Each will be described below.

\subsubsection{Familiarization}

The first block familiarized the pilot with the basic (non-iced) flight characteristics and the ICEFTD pilot controls and instrument panel. This was accomplished by having the pilot perform a takeoff and climb in VMC. Pilots were directed by the instructor to climb to specific altitudes, make turns to headings, and asked to apply longitudinal and lateral inputs to assess normal aircraft handling characteristics. These maneuvers consisted of longitudinal step or doublets and lateral step inputs for various flap settings. These maneuvers were accomplished within a normal traffic pattern after which a flap $30\left(\delta \mathrm{F}=30^{\circ}\right)$ landing was accomplished in VMC. This block typically took about 15 min to accomplish.

\subsubsection{Icing Effects}

The second block demonstrated the effects of the failure ice shapes on wing stall and tail stall characteristics. The exercise was initiated at $8000 \mathrm{ft}$ above ground level with the airplane configured with No-Ice and $\delta \mathrm{F}=0^{\circ}$. The pilot was instructed to reduce power to idle, trim the airplane at approximately $1.3 \mathrm{Vs}(85 \mathrm{kts})$, and then decelerate at 1 knot per second to achieve a full aerodynamic wing stall. Pilots noted speeds for stall warning and full stall, and then recovered to level flight by adding power and reducing angle of attack. Pilots were asked to comment on the basic stall characteristics. Then with the airplane in stabilized flight, the failure ice (All-Ice) would be switched ON. The pilot retrimmed the airplane at $85 \mathrm{kts}$ and performed the wing stall and recovery with the ice on. Pilot comments were taken throughout the maneuver. The next exercise was reinitiated at $8000 \mathrm{ft}$, but with flap set at $20^{\circ}$. Again an idle power wing stall was initiated from $1.3 \mathrm{Vs}(75 \mathrm{kts})$ in the No-Ice and then All-Iced configurations. Because ice and wing flap configurations could be quickly reset, pilots could firmly associate the change in wing stall behavior due to the icing and flap position. Lastly, to emphasize the effect of flap position on tail stall behavior, a flap transition maneuver was accomplished. The exercise was initiated from $8000 \mathrm{ft}$ with failure ice (All-Ice) ON and flaps up. Pilots trimmed the airplane for level flight at $85 \mathrm{kts}$. Then without changing power or elevator trim, the pilots would select flaps $40^{\circ}$ and maintain $85 \mathrm{kts}$ by adjusting only pitch attitude. When the flaps reached full deflection, the pilots were instructed to either add power or reduce power to see the effects that power has on the condition they were experiencing. Also, the pilot was instructed to increase and decrease airspeed by $10 \mathrm{kts}$ to observe the effect that speed 
has on the condition they were experiencing. Lastly, the pilot raised the flaps to return the airplane to its original trim condition and observe the normal flying characteristics of that configuration. This training block typically took about $15 \mathrm{~min}$ to complete.

\subsubsection{Operational Scenario}

The third training block placed the pilot in an operational situation with the iced airplane. This consisted of performing three precision approaches and landings. These exercises were initiated with the airplane at $3000 \mathrm{ft}, 10$ miles south of the airport and offset from the localizer by 1 mile. The initial condition was a speed of $120 \mathrm{kts}$ and flaps up. The pilot was instructed to turn to a heading to intercept the localizer and to have the airplane configured with $20^{\circ}$ or $30^{\circ}$ of flap and slowed to an $85 \mathrm{kts}$ approach speed by the final approach fix. The pilot was cleared for the approach and landing. Pilots with instrument ratings performed the approach tasks in IMC with ceiling set at $200 \mathrm{ft}$, while pilots without instrument ratings performed all tasks in VMC. During the first three days of training, all approaches were conducted with the wing and tail failure case ice condition. Pilots flew the first approach with flap $20^{\circ}$, followed by a second approach with flap $30^{\circ}$, and the third approach with flap $30^{\circ}$ from which a go-around was directed followed by a visual circling approach. While circling, the pilot was then asked to execute a landing at the greatest flap angle possible with reasonable workload and safety. During the second three days of training, the profile was altered slightly. All pilots flew the first approach in the No-Ice baseline and flaps at $30^{\circ}$. The second and third approaches were then flown with the failure case All-Ice condition and at $20^{\circ}$ and $30^{\circ}$ of wing flap, respectively, and in either VMC for inexperienced pilots or IMC for experienced pilots. The purpose of the change was to allow pilots one practice approach to evaluate the basic approach task workload. Experienced pilots were also given 10 knot crosswinds on their third approach. To quantify the impact of icing and wing flap configuration, experienced pilots were asked to evaluate each approach and landing task within specified tolerances using the Cooper-Harper handling quality rating (HQR) system (fig. 10). This training block took about 30 min to complete.

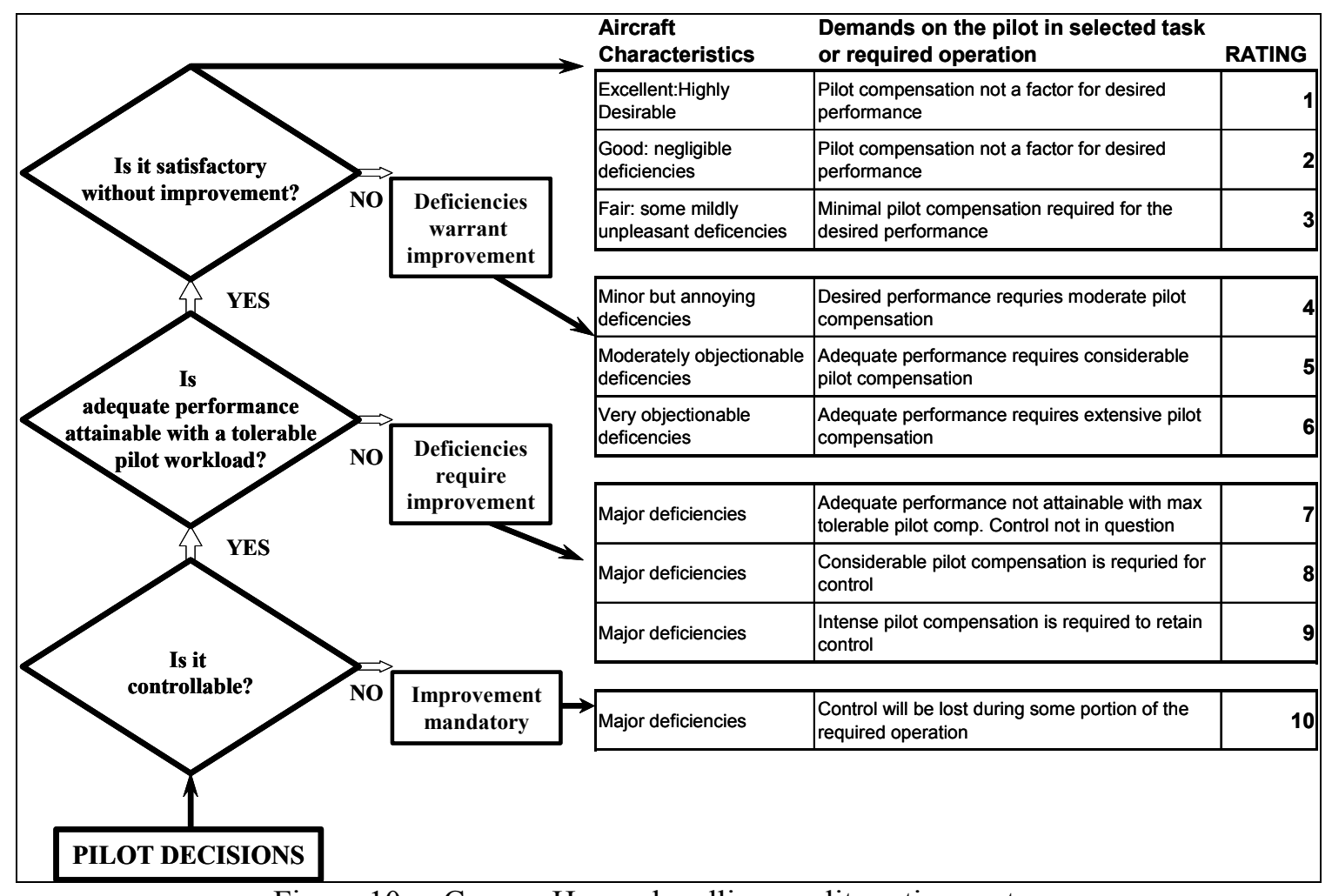

Figure 10.-Cooper-Harper handling quality rating system. 
In total the training sessions took approximately one hour to complete. In this way, these profiles enabled a throughput of about 7 pilots per day. Over the course of six days, forty-one pilots were trained.

\subsection{Results from the Training Sessions}

The range of pilot experience was quite large, from highly experienced test pilots with over $10,000 \mathrm{hr}$ of flight experience to private pilots with very few hours. The following results are generalized from observations and notes made by the NASA and UTSI simulator instructors.

\subsubsection{Familiarization}

The initial takeoff, approach, and landing task in VMC without ice gave pilots a basic familiarity with the simulator, the displays, and the airplane handling characteristics. Pilots performed step inputs and doublets in the flaps $0^{\circ}, 20^{\circ}$, and $30^{\circ}$ settings to experience the normal stability, response and damping characteristics of the uncontaminated airplane. Most pilots found the aircraft to have fairly deadbeat short period response characteristics and fairly heavy control loads in the pitch axis, particularly during the takeoff rotation. Some noted the pronounced effect that flaps had on power requirements. Generally, most found it to be a stable, nice-flying airplane.

\subsubsection{Icing Effects}

These exercises demonstrated stark differences in handling characteristics and pitch control between the non-iced Twin Otter and the Twin Otter with failure case ice shapes. For example, no abrupt pitch or roll tendencies occurred during stalls with the non-iced Twin Otter. However, during stalls with failure ice, pilots experienced and commented on the "roll-off" tendency, especially with flaps set at $20^{\circ}$. These roll-offs resulted in steep bank angles, sometimes reaching or exceeding $90^{\circ}$. Figure 11 contains plots from one of the flap $20^{\circ}$ stalls. The first $100 \mathrm{sec}$ shown is a stall maneuver for the No-Ice configuration.

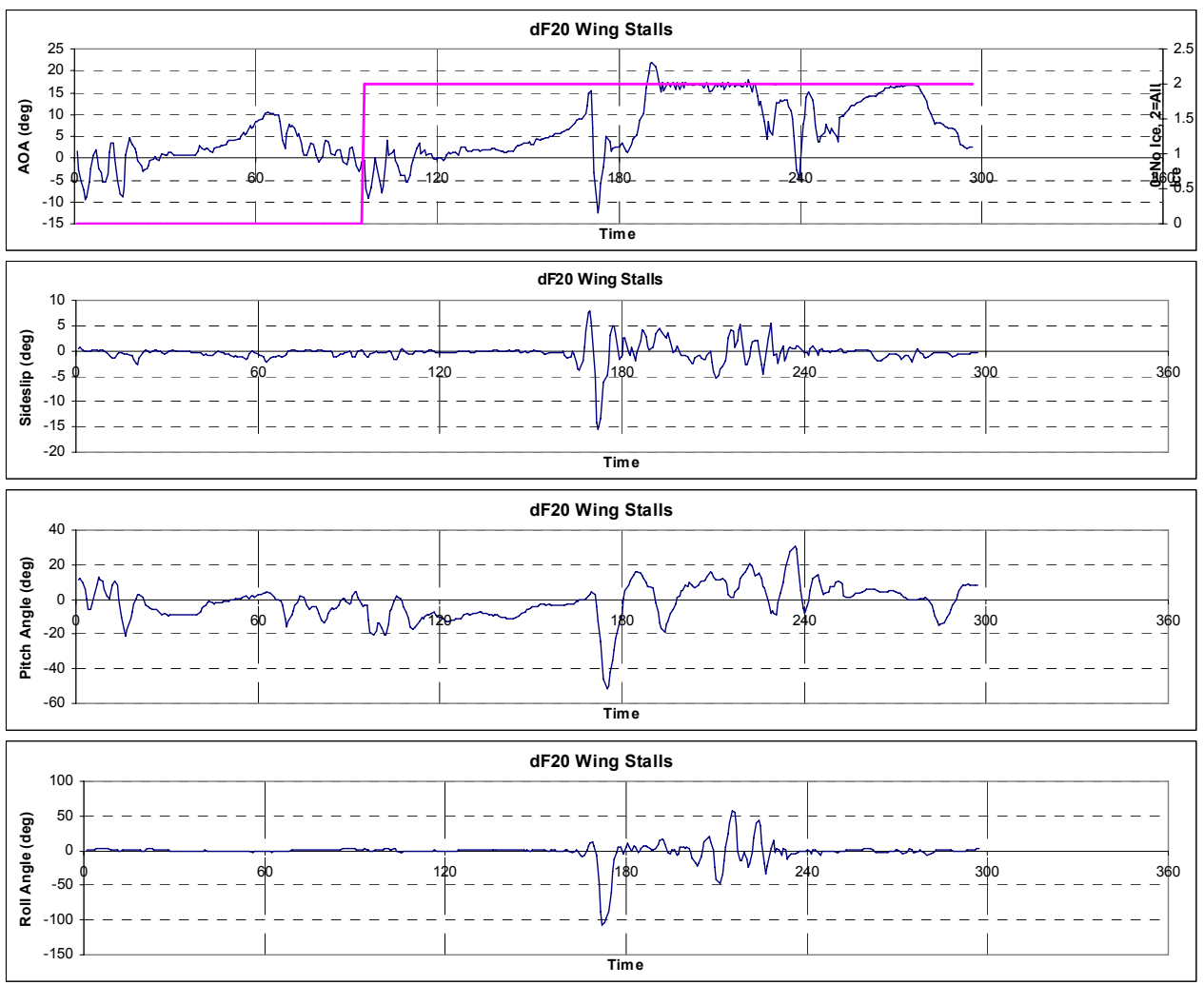

Figure 11.-Flap $20^{\circ}$ wing stalls (No-Ice and All-Ice). 
Note that there were no strong roll off or pitch down tendencies at $70 \mathrm{sec}$ when the stall angle was achieved. After $100 \mathrm{sec}$, the All-Ice switch was enabled, and the stall maneuver with ice was performed. Observe at about $170 \mathrm{sec}$ the abrupt stall with large sideslip and roll angles (nearly $-100^{\circ}$ ) during the recovery. Also note the pitch angle achieved a $50^{\circ}$ nose down attitude during the recovery.

During flap transitions with failure ice, pilots noted flap position in relation to the first signs of controllability problems. Many pilots expressed some surprise when encountering the very high control forces associated with wing flap extension, and discovered the difficulty in maintaining good pitch attitude control. All pilots experienced large pull forces to maintain $85 \mathrm{kts}$ as flaps transitioned beyond $20^{\circ}$, and when the column force also became oscillatory, most were unable to maintain good airspeed control. As power was added, the forces increased and when power was set to idle, the forces decreased. Likewise, as airspeed increased, the pull forces increased and were more oscillatory and when airspeed was decreased, the forces and oscillations were reduced. When flaps were raised, all noted that the forces and oscillations went away when flaps were less than $15^{\circ}$. This introduction provided a necessary practice and orientation for the more difficult approach tasks that followed.

\subsubsection{Operational Scenarios}

These exercises were developed to provide realistic pilot task with the iced aircraft. Since icing issues often arise during the approach and landing phases, it was appropriate to look at these phases for the exercise. Performing the approach using basic instrument displays required a higher pilot workload to perform the task. From the outset it was apparent that for some pilots, the workload was high in order to fly the basic IMC approach task using the raw data glide slope and localizer presentation. This was the reason for changing the training profile during the second week, so pilots could get a feel for the basic task workload with no compensation for ice, and comparisons on the pilot performance and HQR's could be made between the No-Ice and All-Ice configurations.

No-ice approach and landing.- - This first IMC task allowed the pilots an opportunity to understand the workload of the basic task, while developing their instrument scan. Pilot performance and ratings indicated good flying qualities with relatively low levels of pilot compensation required to meet the desired performance of the task. This exercise was initiated in the clouds, and the pilot was given heading and altitude instructions to intercept the localizer. The flaps were transitioned from $\delta \mathrm{F}=0^{\circ}$ to

$\delta \mathrm{F}=30^{\circ}$ by the final approach fix, and the pilot was to maintain $85 \mathrm{kts}$ on final approach. The pilot made power changes and trim changes accordingly as flaps and speed were set to maintain descent rate along the glide slope. All pilots were able to trim the airplane and fly with one hand on the yoke, and one hand on the throttle.

Data from one of these approaches are shown in figures 12 and 13. This pilot felt the workload was fine; he could make radio frequency changes, read maps, etc. It took him some time to get established on airspeed and had some lateral overshoots on the localizer. Overall, he rated the task with an HQR $=3$ (aircraft characteristics were fair with some mildly unpleasant deficiencies, but desired performance was achieved without improvement).

All-iced approach and landing.-Pilot performance and HQR's for the approach and landing in the All-Ice configurations generally indicated a much more challenging airplane to fly. The second and third approaches were made with All-Ice and $\delta \mathrm{F}=20^{\circ}$ and $\delta \mathrm{F}=30^{\circ}$, respectively. When the flaps were lowered, the control anomalies experienced during the flap transition were revisited. With $\delta \mathrm{F}=20^{\circ}$, a slight pull force was required even with full-nose up trim in order to maintain the 85 knot target approach speed. With $\delta \mathrm{F}=30^{\circ}$, a significant pull force $(15 \mathrm{lb})$ was required to maintain $85 \mathrm{kts}$. Force oscillations occurred on top of these steady pull forces, making speed and attitude control difficult. Most pilots used two hands on the yoke to control the airplane. Many pilots found that the workload associated with flying an approach to CAT I minimums with the failure case icing condition was in many cases at the limits of their abilities. Handling problems were caused by horizontal tail ice, but the task was further complicated by the failure ice on the wing, which resulted in lateral control problems at low speed near wing stall. Some pilots encountered wing stalls because the longitudinal handling problems made it difficult to 


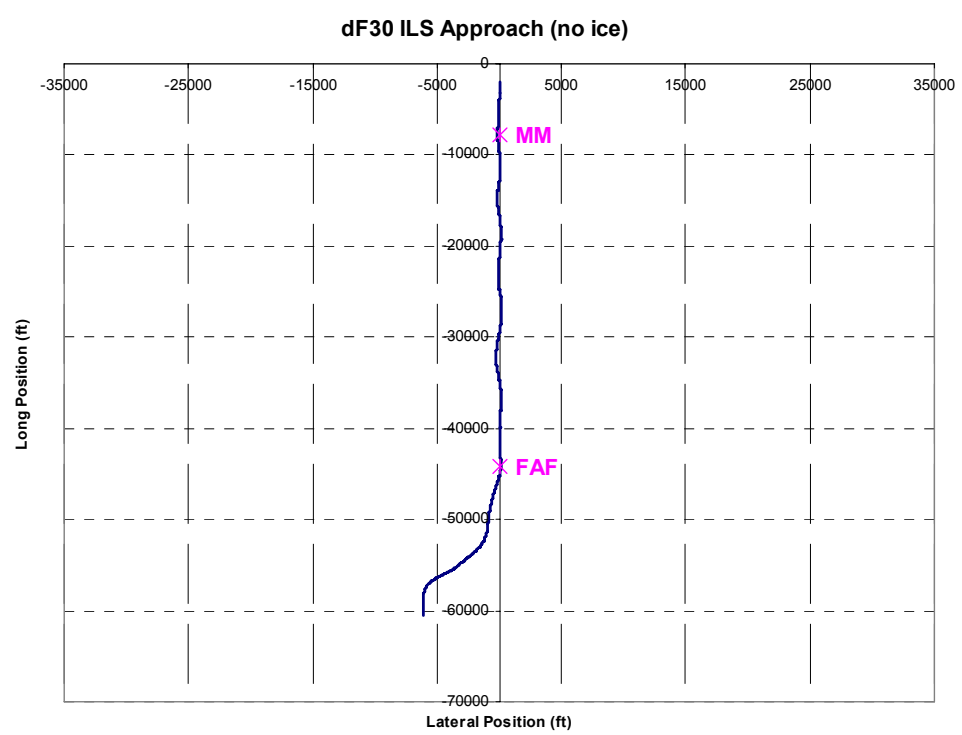

Figure 12.-Position trace-Flap $30^{\circ}$ approach (No-Ice).
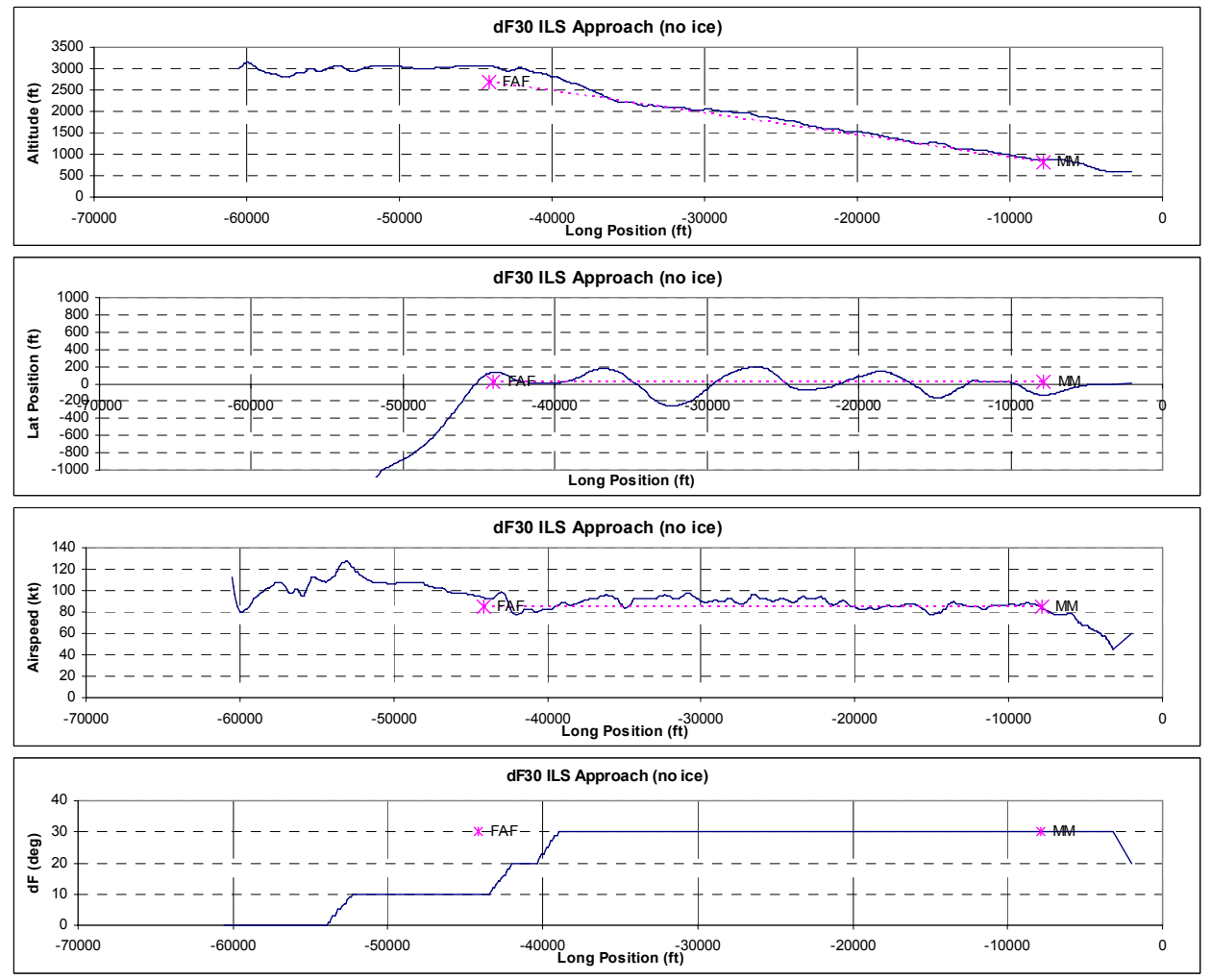

Figure 13.-Flap $30^{\circ}$ approach (No-Ice); data referenced to position.

control airspeed. In some cases, wing stall recoveries were difficult due to the high induced drag at high angle of attack and low altitude. Increased power was not enough to break the stall, and there was not much altitude to exchange for airspeed. These cases would sometimes result in a crash. All experienced pilots found that most of their attention had to be devoted to controlling pitch to achieve vertical path performance. This element of the task consumed most of their attention because of icing related instability, high control forces, inability to trim, and related pitch control anomalies. Although not sensed by the pilot, during the pitch excursions, the G-meter would often cycle between 0 to $2.5 \mathrm{G}$. Because of 
the intense amount of attention required for pitch control using a basic attitude indicator, lateral path performance and airspeed control usually suffered.

Data from one of these approaches is shown in figures 14 to 16 . This pilot had difficulty throughout the approach. Airspeed was consistently high, which made the pitch control more difficult. Power changes were large and abrupt, which degraded handling further. Concentrating on the longitudinal problems, he failed to intercept the localizer initially and had multiple lateral overshoots throughout the approach. Towards the middle of the approach, the large pitch oscillations caused multiple stall warnings

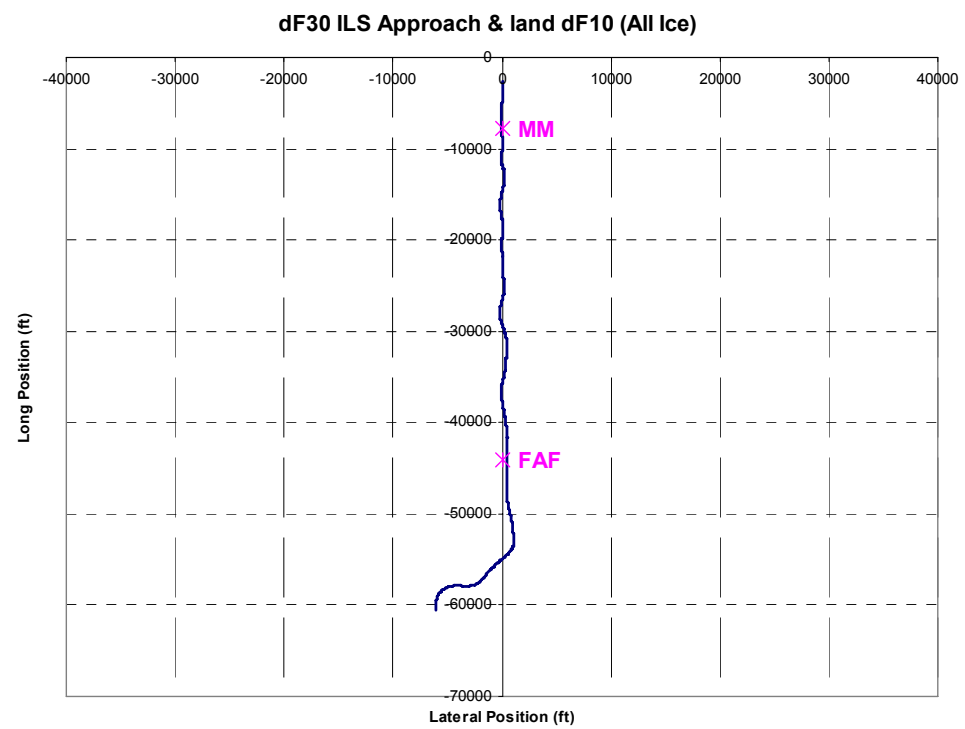

Figure 14.-Position trace-Flap 30 approach (All-Ice).
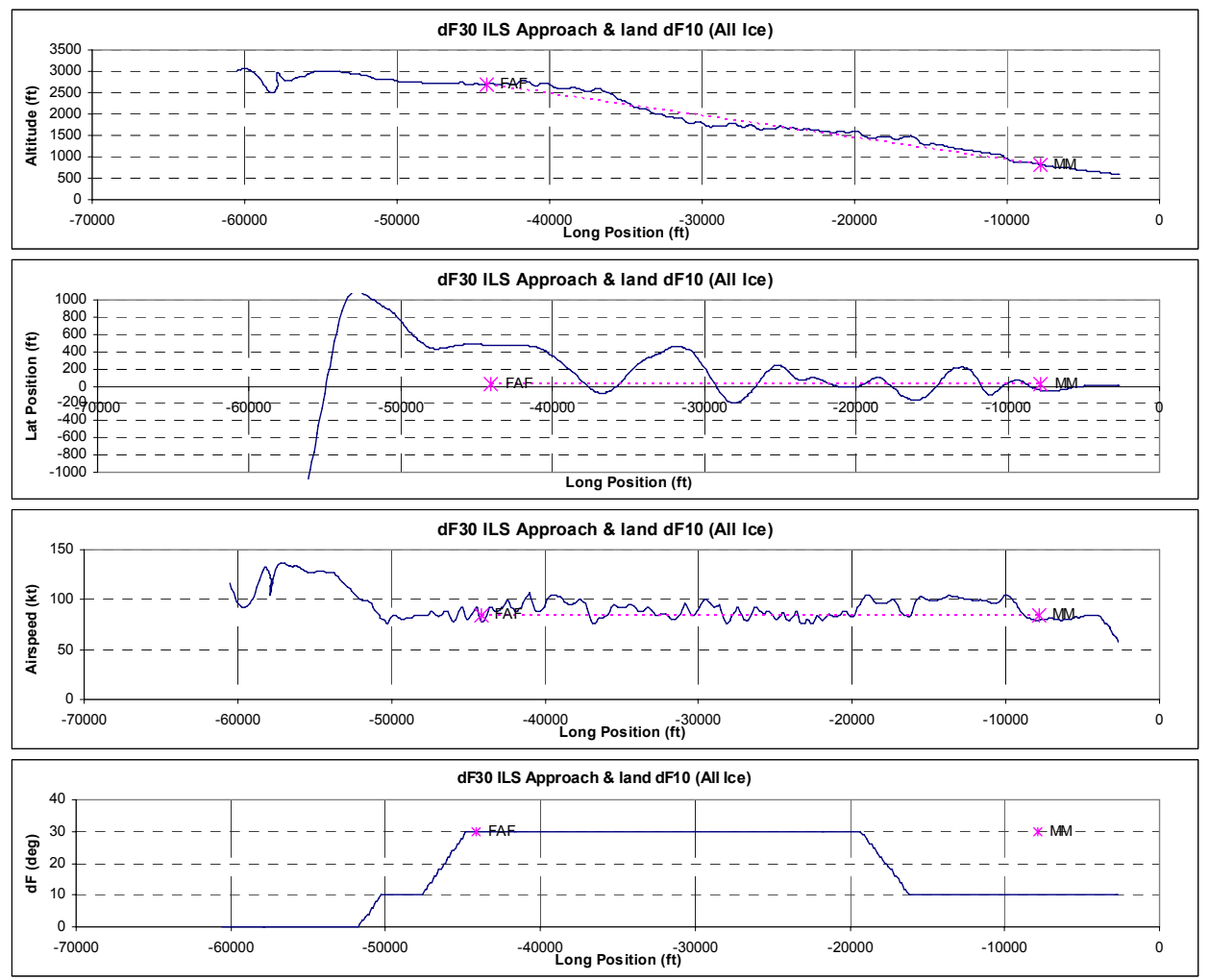

Figure 15.-Flap 30 approach (All-Ice); data referenced to position. 

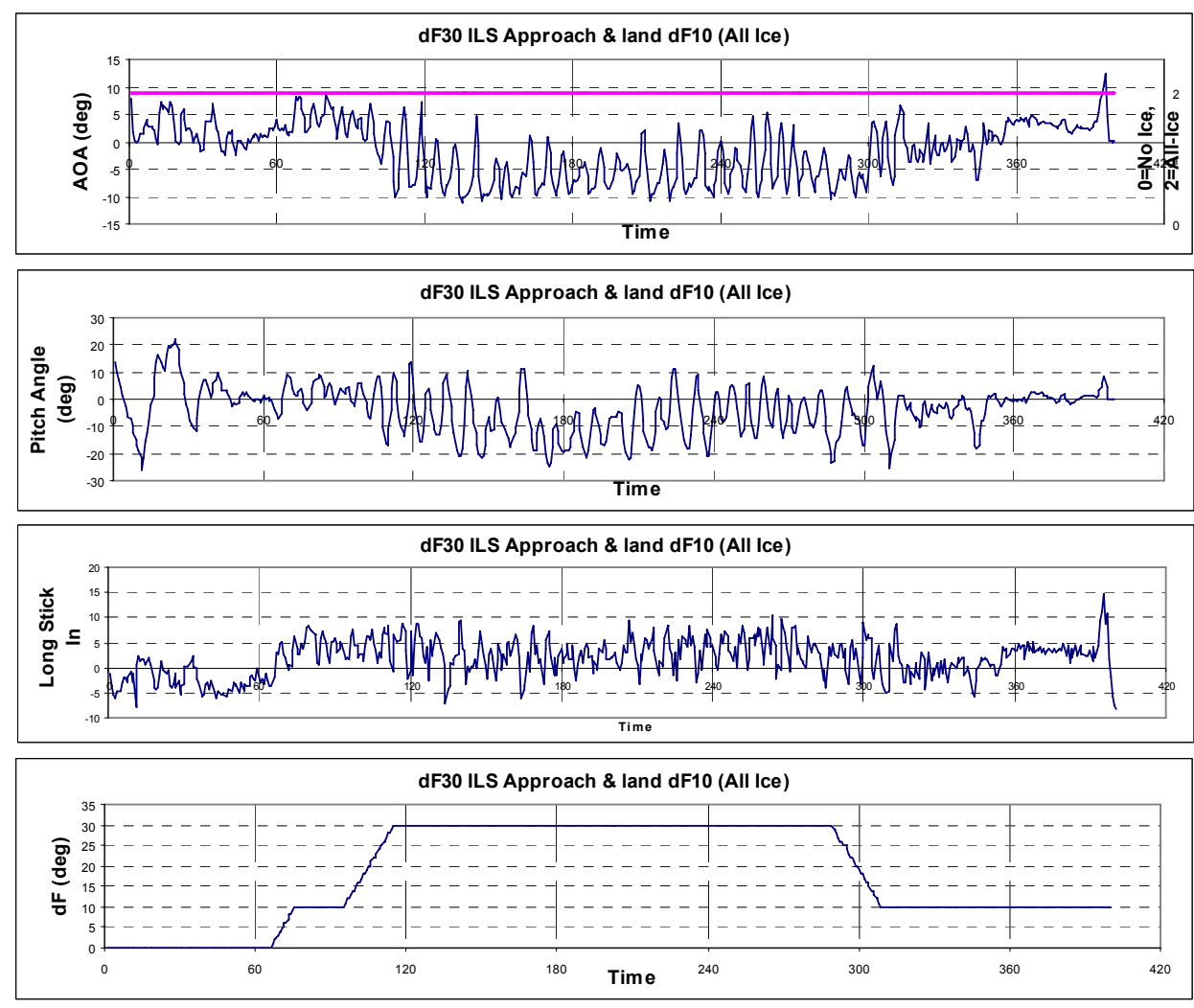

Figure 16.-Flap $30^{\circ}$ approach (All-Ice) time history.

as $\mathrm{G}$ was increased and airspeed decreased. Since it was clear that the pilot was task saturated, the instructor suggested raising the flaps to $10^{\circ}$ to finish the approach. The workload was considerably deceased with this configuration, and the pilot was able to successfully land the airplane. Note in figure 16 when flaps reached $10^{\circ}$, the oscillations in angle of attack, pitch angle, and longitudinal input were greatly reduced. This pilot rated the iced airplane with $\delta \mathrm{F}=30^{\circ}$ as an $\mathrm{HQR}=10$ (aircraft characteristics have major deficiencies, and that control would be lost during some point of the operation).

\subsubsection{Handling Quality Ratings}

After each approach and landing, pilots familiar with HQR's were asked to use the Cooper-Harper chart in figure 10 to rate their ability to complete the approach and landing tasks within specific adequate and desired performance metrics. The HQR's from sixteen pilots who performed the approaches in the No-Ice $/ \delta \mathrm{F}=30^{\circ}$, All-Ice $/ \delta \mathrm{F}=20^{\circ}$, and All-Ice $/ \delta \mathrm{F}=30^{\circ}$ configurations were compiled into figure 17 .

For the No-Ice, $\delta \mathrm{F}=30^{\circ}$ configuration, pilots rated the approach and landing between an $\mathrm{HQR}=2$ to $\mathrm{HQR}=4$. Many pilots commented on the lack of practice as contributing to the higher rating, and this point should be considered in using the actual $\mathrm{HQR}$ number. Even without much practice, the general rating was that desired performance was achieved and aircraft characteristics were good to fair with some deficiencies.

For the All-Ice, $\delta \mathrm{F}=20^{\circ}$ configuration, pilot ratings ranged from an $\mathrm{HQR}=4$ to 9 . The increase in the ratings was certainly due to the reduced stability and controllability as well as the handling anomalies associated with icing. The increased spread in the numbers reflected to some degree the skill level and experience of the individual pilot receiving the training. Additionally, the spread could have been influenced by the "learning curve" or proficiency gained as the training progressed and pilots became more familiar with the displays and aircraft characteristics. This was an expected result as pilot task performance generally improved with practice and it did affect pilot ratings. In a more rigorous pilot 
Cooper-Harper Handling Quality Ratings for Various

Approach \& Landing Configurations

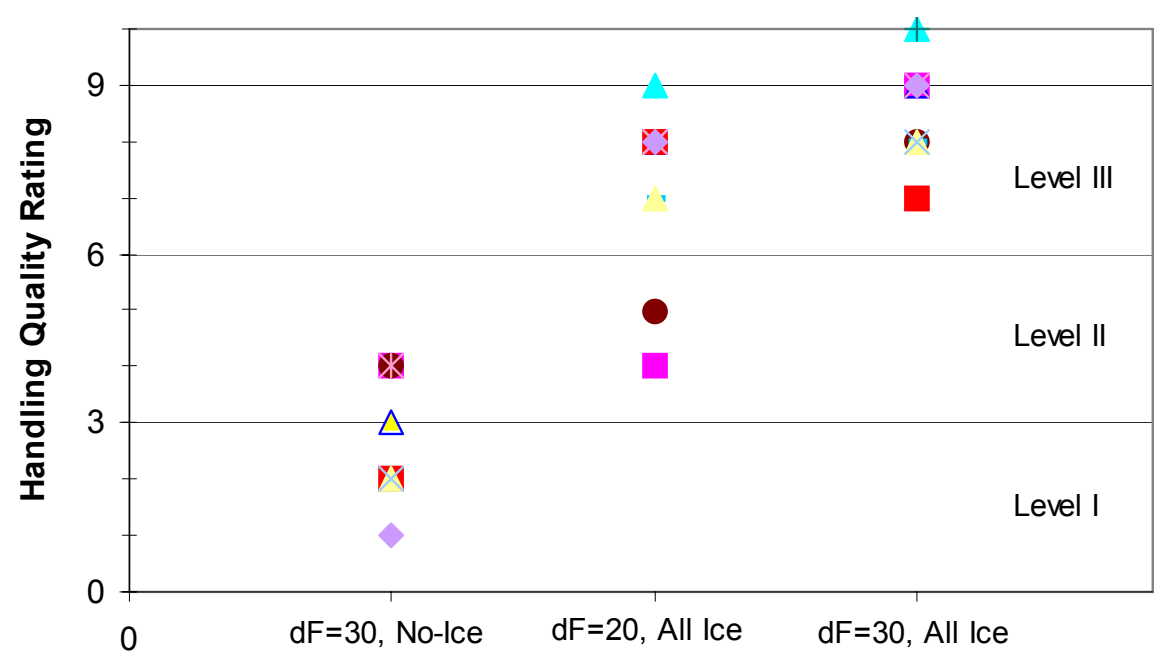

Figure 17.-Cooper-Harper ratings.

evaluation setting, a certain amount of time would be given to pilots to develop a baseline level of proficiency and familiarization before rating a task.

For the All-Ice, $\delta \mathrm{F}=30^{\circ}$ configuration, pilot ratings ranged from an $\mathrm{HQR}=7$ to 10 . This increase in the ratings reflects the increased workload associated with the greater amount of pilot compensation at the higher flap setting. In this configuration, none of the pilots were able to meet the adequate performance metrics of the approach due to the inability to trim, the large and oscillating column forces, large pitch excursions when making power changes (one-handed operation), and loss of situational awareness on the lateral position. As stated above, some pilots encountered wing stalls and were unable to recover in this configuration due to increased drag and limited altitude. Although most pilots rated the $\delta \mathrm{F}=30^{\circ}$ approach the worst case condition, a few rated this task slightly better (lower compensation) than the $\delta \mathrm{F}=20^{\circ}$ approach. These pilots felt that the proficiency acquired on the $\delta \mathrm{F}=20^{\circ}$ approach, which was flown before they flew the technically more difficult $\delta \mathrm{F}=30^{\circ}$ approach, was the reason. Overall, pilot ratings accurately reflected the inability of meeting performance requirements with flaps extended. Most pilots exited the training device perspiring freely and commenting that no additional workout was needed for the rest of the day. These comments confirmed the physical effort and intense concentration required to perform the training tasks.

\subsection{Pilot Comments on ICEFTD Training Sessions}

All pilots commented very favorably on their training experience and the applicability it had to their present occupations. Pilots who had participated in development programs for aircraft with reversible controls identified strongly with the characteristics shown by the ICEFTD. Others who had not had this experience were in general surprised by the amount of effort it took to perform the given tasks. None had ever encountered the levels of control forces or feedback activity as was demonstrated during this simulation. One pilot commented that he recently completed an extensive icing development and certification program on a Part 25 business jet with a major aerospace company. During the development phase with 22.5 min ice shapes on the horizontal tail leading edge, he observed large, uncommanded stick pumping and pitch transients when flaps were moved to the landing configuration. He also noted that the aircraft could not be trimmed at the approach speed. Stick pumping developed and strengthen as the aircraft accelerated with increase power setting. The simple procedure of raising the flaps to the last setting completely eliminated the problem. This pilot was pleasantly surprised to observe that the ICEFTD accurately simulated the same phenomenon that he had experienced, even though the two 
aircraft were radically different in design, tailplane configuration, and powerplant. The lectures and the ICEFTD demonstration gave him a clear understanding of what he had experienced during their icing program. He strongly recommend the ICEFTD to any flight test crew (test pilots and flight test engineers) who are in the process of preparing for an icing development or certification program. He considered this training a "must have"!

\subsection{Instructor's Observations and Recommendations}

One interesting observation was that inexperienced pilots flying in VMC sometimes could manage the controllability issues better than the experienced pilots flying in IMC. The availability of the three screen visual cues, which is equivalent to flying in VMC, greatly reduced the basic approach task workload. Lateral and vertical path control was greatly simplified due to the availability of the visual scene, which reduced the need for an efficient instrument scan. Pilots could therefore focus most of their attention on dealing with control issues while little attention was needed to correct for lateral and vertical path error. Many of the VMC approaches flown in the failure case condition by the inexperienced pilots sometimes resulted in at least adequate performance. However, when one low-time instrument-rated pilot who was doing very well in VMC tried performing the approach in IMC, he crashed.

The workload associated with the basic IMC approach task made a significant difference in the pilot's ability to meet either the desired or adequate performance criteria in the failure case ice shape configuration. We think this is a very important observation that should be considered when performing actual aircraft handling evaluations with ice shapes, especially if an aircraft displays handling differences with failure case ice. Even minor handling deficiencies coupled with a high workload task can result in unacceptable "average pilot" performance. The draft Advisory Circular 25.21-1X proposes that approaches be made with failure case ice, but does not specify that the pilot executing these approaches perform them with vision restricting devices. Another consideration is that when first encountering an icing failure case the average pilot may not have the benefit of a "learning curve" as was recognized by most pilots participating in this training.

\subsection{Closing Remarks}

The Ice Contamination Effects Flight Training Device was successfully demonstrated to eighty-four pilots and flight test engineers through four venues. Training sessions familiarized pilots with the aircraft simulation, illustrated differences in wing and tail stall character due to ice shapes, identified cues and variables that reduce or exacerbate the problems, and, lastly, placed the pilots in an operational scenario with the iced aircraft to demonstrate the potential extent of the problem icing can pose. All of the pilots who participated in the demonstrations were complimentary of the ICEFTD and found the training to be applicable to their occupations.

The ICEFTD successfully demonstrated that icing effects can be modeled accurately in flight training devices to show how they alter flying qualities significantly. Clearly, simply adding weight and increasing drag in pilot training simulators does not sufficiently model the change in stall characteristics that pilots would experience in real-world operations. Based on the potential safety benefits of this training, the authors recommend that the technology demonstrated herein be considered for incorporation in current full flight simulators or flight training devices.

The ICEFTD was continually improved throughout the demonstrations through the feedback provided by the participants. Additional improvements are certainly possible, as are new applications. The

reconfigurable nature of the software enables new research areas to be explored. One potential area is comparing the effects icing has on reversible to irreversible control systems. These topics may be considered in future efforts. 


\subsection{References}

1. Russell, P., Pardee, J., "Joint Safety Analysis Team- CAST Approved Final Report Loss of Control JSAT Results and Analysis," December 2000.

2. Papadakis, M., Gile Laflin, B.E., Youssef, G.M, and Ratvasky, T.P., "Aerodynamic Scaling Experiments with Simulated Ice Accretions," AIAA 39th Aerospace Sciences Meeting and Exhibits, Jan. 8-11, 2001, Reno, NV, AIAA Paper 2001-0833.

3. Gingras, D.R., Dickes, E.G., Ratvasky, T.P., and Barnhart, B.P., "Modeling of In-Flight Icing Effects for Pilot Training," AIAA Modeling and Simulation Technologies Conference and Exhibit, Aug. 5-8, 2002, Monterey, CA, AIAA Paper 2002-4605.

4. Barnhart, B., Dickes, E., Gingras, D., Ratvasky, T., "Simulation Model Development for Icing Effects Flight Training," SAE-2002-01-1527, April 2002.

5. Ratvasky, T., Blankenship, K., Rieke, W., Brinker, D., "Iced Aircraft Flight Data for Flight Simulator Validation," SAE-2002-01-1528, April 2002.

6. Ratvasky, T.P., Ranaudo, R.J., Barnhart, B.P., Dickes, E.G., and Gingras, D.R., "Development and Utility of a Piloted Flight Simulator for Icing Effects Training," AIAA 41st Aerospace Sciences Meeting and Exhibit, Jan. 6-9, 2003, Reno, NV, AIAA Paper 2003-0022.

7. Mauro, R., Barshi, I., "Training Smart: Using Principles of Cognitive Science in Aeronautical Education and Training," AIAA-2003-20, January 2003.

8. Ratvasky, T.P., Van Zante, J.F., Sim, A., "NASA/FAA Tailplane Icing Program: Flight Test Report," NASA TP-2000-209908, DOT/FAA/AR-99/85, March 2000.

9. “Tailplane Icing," NASA Glenn, 1998, http://icebox-esn.grc.nasa.gov/ext/education/video/video.html

10. "Icing For General Aviation", NASA Glenn, 2001, http://icebox esn.grc.nasa.gov/ext/education/video/video.html 
Public reporting burden for this collection of information is estimated to average 1 hour per response, including the time for reviewing instructions, searching existing data sources, gathering and maintaining the data needed, and completing and reviewing the collection of information. Send comments regarding this burden estimate or any other aspect of this collection of information, including suggestions for reducing this burden, to Washington Headquarters Services, Directorate for Information Operations and Reports, 1215 Jefferson Davis Highway, Suite 1204, Arlington, VA 22202-4302, and to the Office of Management and Budget, Paperwork Reduction Project (0704-0188), Washington, DC 20503.

\begin{tabular}{|l|c|c|}
\hline 1. AGENCY USE ONLY (Leave blank) & $\begin{array}{c}\text { 2. REPORT DATE } \\
\text { May } 2006\end{array}$ & $\begin{array}{r}\text { 3. REPORT TYPE AND DATES COVERED } \\
\text { Technical Memorandum }\end{array}$ \\
\hline
\end{tabular}

\section{TITLE AND SUBTITLE} 5. FUNDING NUMBERS

Demonstration of an Ice Contamination Effects Flight Training Device

\section{6. $\operatorname{AUTHOR(S)}$}

WBS-609866.02.07.03.02

Thomas P. Ratvasky, Richard J. Ranaudo, Kurt S. Blankenship, and Sam Lee

7. PERFORMING ORGANIZATION NAME(S) AND ADDRESS(ES)

National Aeronautics and Space Administration

John H. Glenn Research Center at Lewis Field

Cleveland, Ohio 44135-3191
8. PERFORMING ORGANIZATION REPORT NUMBER

E-15480

\section{SPONSORING/MONITORING AGENCY NAME(S) AND ADDRESS(ES)}

National Aeronautics and Space Administration

Washington, DC 20546-0001

10. SPONSORING/MONITORING AGENCY REPORT NUMBER

NASA TM-2006-214233

AIAA-2006-0677

\section{SUPPLEMENTARY NOTES}

Prepared for the 44th Aerospace Sciences Meeting and Exhibit sponsored by the American Institute of Aeronautics and Astronautics, Reno, Nevada, January 9-12, 2006. Thomas P. Ratvasky and Kurt S. Blankenship, NASA Glenn Research Center; Richard J. Ranaudo, University of Tennessee Space Institute, 411 B.H. Goethert Pky, Tullahoma, Tennessee 37388; and Sam Lee, QSS Group, Inc., 21000 Brookpark Rd., Cleveland, Ohio 44135. Responsible person Thomas P. Ratvasky, organization code RTI, 216-433-3905.

12a. DISTRIBUTION/AVAILABILITY STATEMENT 12b. DISTRIBUTION CODE

Unclassified - Unlimited

Subject Categories: 05 and 08

Available electronically at http://gltrs.grc.nasa.gov

This publication is available from the NASA Center for AeroSpace Information, 301-621-0390.

13. ABSTRACT (Maximum 200 words)

The development of a piloted flight simulator called the Ice Contamination Effects Flight Training Device (ICEFTD) was recently completed. This device demonstrates the ability to accurately represent an iced airplane's flight characteristics and is utilized to train pilots in recognizing and recovering from aircraft handling anomalies that result from airframe ice formations. The ICEFTD was demonstrated at three recent short courses hosted by the University of Tennessee Space Institute. It was also demonstrated to a group of pilots at the National Test Pilot School. In total, eighty-four pilots and flight test engineers from industry and the regulatory community spent approximately one hour each in the ICEFTD to get a "hands on" lesson of an iced airplane's reduced performance and handling qualities. Additionally, pilot cues of impending upsets and recovery techniques were demonstrated. The purpose of this training was to help pilots understand how ice contamination affects aircraft handling so they may apply that knowledge to the operations of other aircraft undergoing testing and development. Participant feedback on the ICEFTD was very positive. Pilots stated that the simulation was very valuable, applicable to their occupations, and provided a safe way to explore the flight envelope. Feedback collected at each demonstration was also helpful to define additional improvements to the ICEFTD; many of which were then implemented in subsequent demonstrations.

14. SUBJECT TERMS

Aircraft icing; Flight simulation; Flight simulators; Flight safety 15. NUMBER OF PAGES 23

\begin{tabular}{|c|c|c|}
\hline $\begin{array}{c}\text { 17. SECURITY CLASSIFICATION } \\
\text { OF REPORT } \\
\text { Unclassified }\end{array}$ & $\begin{array}{c}\text { 18. SECURITY CLASSIFICATION } \\
\text { OF THIS PAGE } \\
\text { Unclassified }\end{array}$ & $\begin{array}{c}\text { 19. SECURITY CLASSIFICATION } \\
\text { OF ABSTRACT } \\
\text { Unclassified }\end{array}$ \\
\hline
\end{tabular}



